\title{
Experimental Validation of Icing Rate Using Rotational Load
}

\author{
Umair N. Mughal ${ }^{1 \mathrm{a}}$, Muhammad S. Virk ${ }^{1}$, Kenji Kosugi² ${ }^{2}$ and Shigeto Mochizuki² \\ ${ }^{\text {I} A r c t i c ~ T e c h n o l o g y ~ R e s e a r c h ~ G r o u p, ~ D e p a r t m e n t ~ o f ~ I n d u s t r i a l ~ E n g i n e e r i n g, ~ U i T ~ T h e ~ A r c t i c ~ U n i v e r s i t y ~ o f ~ N o r w a y, ~ N a r v i k-8505, ~ N o r w a y ~}$ \\ ${ }^{2}$ Cryospheric Environment Laboratory, Snow and Ice Research Center, NIED, Shinjo 996-0091, Japan
}

Correspondence Email: aumair.n.mughal@uit.no

\begin{abstract}
Icing load and icing rate are necessary feedback variables for an intelligent anti/de-icing system to work effectively in harsh cold environment of high north. These parameters may be measured by axial loadings or by rotational loadings, as a function of current demand. However the former may not necessarily be dynamic, whereas the later necessarily be rotational. Sufficiently at a fixed rpm, a mathematical model between additional polar moment of inertia vs electrical demand of the sensor can be established to analytically shape the icing load and icing rate adequately as hypothesized in Cost 727. This paper aims to develop such model and is validated using experimental data from a case study conducted by Atmospheric Icing Research Team of Narvik University College at Cryospheric Environmental Simulator, Snow and Ice Research Center, (NIED) Japan.
\end{abstract}

Keywords: Atmospheric Ice, Rotational Loading; Icing Sensor; Validation; Calibration; Cryospheric Environmental Simulator

\section{Introduction}

Generally atmospheric icing is considered as a potential hazard for structures particularly in polar domains. Icing is often accepted as an inconvenience, but that tolerance can rapidly become a safety hazard that may require solutions [1]. To reduce the effects of atmospheric ice accretion, necessary design modifications coupled with selective anti/de-icing system is required for these structures/platforms. An efficient anti/de icing system is some how dependent upon the information from the atmospheric icing sensors and works on the principle to optimize the energy demand based upon the feedback related with accreted icing load, icing rate and preferably ice type information from the icing sensor. Therefore the most important variables for an icing sensor are icing load and icing rate. Today there are few available solutions/sensors that can measure icing load and icing rate, such as IceMonitor ${ }^{\mathrm{TM}}$ by Combitech [2], Sweden and IceMeter ${ }^{\mathrm{TM}}$ by IAP, Czech Republic [3] which work using load cells. Both of these sensors use axial load physics to measure the required parameters. Also HoloOptics icing rate sensor [4] uses near infrared electromagnetic band absorption scheme to distinguish between different types of ice whereas Rosemount icing sensor uses ultrasonic probe based upon magnetostrictive technology to measure icing rate. One possible drawback with most of these sensors is the non-symmetric distribution of the ice load around the sensor as due to free rotation, ice deposit on the windward side and hence the wind loads on icing sensor generally effect the resultant icing load measurements. Also there are some recommended changes in icemeter as mentioned in [5],

i. Possibility to build an instrument with a rotating collector.

ii. More focus on the sensors that measure accumulated icing.

These recommendations are based upon a hypothesis without any analytical or experimental validation. Keeping in view the limitations of available sensors in the market, a prototype atmospheric icing sensor as been developed by Atmospheric Icing Research Team. This sensor utilizes rotational load measurement physics for measuring icing load and icing rate together with capacitive loading to detect an atmospheric icing event, icing type and melting rate. In this paper, an analytical relationship between a motor's load (at fixed rpm) and current is aimed to be developed in order to analytically and experimentally support the hypothesis during the research expedition at Cryospheric Environmental Simulator, Shinjo, Japan. This sensor utilizes constantly slowly rotation for two purposes,

i. To measure icing load and icing rate using rotational physics

ii. To provide uniform deposition of atmospheric ice on the capacitive plates 


\section{Curvilinear Motion}

In Figure 1 the curvilinear motion is shown in the general form where $\phi$ denotes the angle between the force $F$ and radius vector $r$ position. According to Newton's second law, force vector that produces $m a$ is represented by normal and tangential components, namely,

$$
m \vec{a}=a_{t} \hat{t}+a_{n} \hat{n}=m \rho \alpha \hat{t}+m \rho \omega^{2} \hat{n}
$$

Equation 1

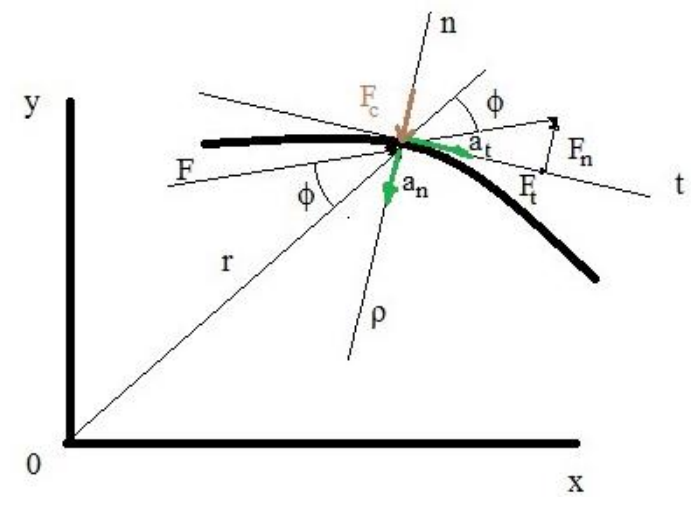

Figure 1. Curvilinear Motion

where $\hat{n}$ is the unit normal vector, $\hat{t}$ is the unit tangential vector, $a_{n}$ is the normal component of acceleration directed to the center of the circle and $a_{t}$ is the tangential component of the acceleration for an object. Note that the position vector $\vec{r}$ in Figure 1 is other than $\rho$ which is the radius of curvature of the field. However if the motion is on a cylinder of radius $\vec{r}$ then it is reasonable to assume that the magnitude of $|\vec{r}|=\rho$. Similarly if a body of mass $M$ with an effective radius $k$ passing through its center of mass will have a mass moment of inertia $J$, given as,

$$
J_{\text {Center of Mass }}=M k^{2}
$$

Equation 2

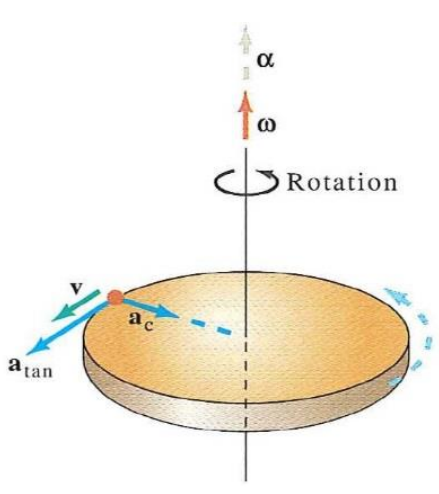

(a). Rotational Motion

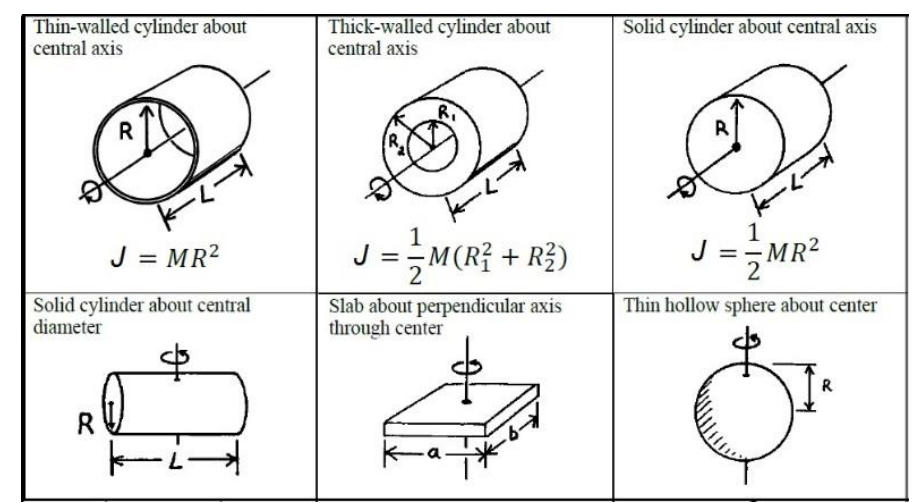

(b). Mass moment of inertia of other circular geometries

Figure 2. Mass Moment of Inertia [6]

The mass moment of inertia of other circular geometries can also be found, the results can be seen in Figure $2 b$. Sufficiently the mass moment of inertia of same body of mass $M$ around any other axes can be determined using the Parallel Axis Theorem which states, the rotational inertia of an object about any axis is given by the sum of the rotational inertia about an axis that goes through the center of mass and is parallel to the given axis, and of the product of the total mass $M$ of the object and the square of the perpendicular distance d between the two axes. Mathematically it can be written as,

$$
J_{\text {Axis at distance d }}=J_{\text {Center of Mass }}+M d^{2}
$$


If it is considered that the system is only rotating at constant rpm $\Omega$, then the Kinetic Energy $K . E$. of the system can be written as Equation 4,

$$
K . E .=\frac{1}{2} J \Omega^{2}
$$

Equation 4

\section{Analytical Study of Rotational Load Measurement}

The physics for measuring forces in curvilinear motion in any system should start by an energy method or principle of conversation of energy. For rotational loading measurements it is typically considered that the electromechanical systems follow the law of conversation of energy, which is given as,

Input from Electric Source = Mechanical Output + Increase in Stored Magnetic Field + Loss (Heat, Sound, etc)

\subsection{Power-Loading Relationship}

Typically, the power input to the motor could be described as,

$$
P_{\text {in }}=P_{\text {in }}\left(V_{\text {in }}, I_{\text {in }}\right)=\alpha V_{\text {in }} I_{\text {in }}
$$

Equation 5

where $P_{\text {in }}$ is power input, $V_{\text {in }}$ is voltage input, $I_{\text {in }}$ is the current input and $\alpha$ can be any constant (e.g. calibration constant). Similarly the power output can be defined as,

$$
P_{\text {out }}=P_{\text {out }}\left(K \cdot E_{\text {out }}, \omega_{m}\right)=\beta K \cdot E_{\text {out }} \Omega_{m}=P_{\text {in }}-\eta
$$

Equation 6

where $P_{\text {out }}$ is power output, $K . E_{\text {out }}$ is the kinetic energy output, $\beta$ is calibration constant, $\eta$ defines the losses (field loss, armature loss, rotational losses etc.) associated with the motor performance and $\Omega_{m}$ is the angular speed of the load.

\subsection{Current-Inertia Relationship}

Equation 4 can also be rewritten as,

$$
K . E_{\text {out }}=\gamma J \Omega_{m}^{2}
$$

Equation 7

where $\gamma$ is any constant (e.g. calibration constant). Using Equation 5 and Equation 7 in Equation 6 , we Equation 8 can be formed.

$$
\alpha V_{i n} I_{\text {in }}-\eta=\beta \gamma J \Omega_{m}^{3}
$$

Equation 8

Equation 8 can be simplified to formulate Equation 9

$$
J=a I_{\text {in }}+b
$$

Equation 9

where $a=\alpha V_{i n} / \beta \gamma \Omega_{m}^{3}$ and $b=-\eta / \beta \gamma \Omega_{m}^{3}$, are constants. The Equation 9 is named as Current - Inertia or $I-J$ relationship. This shows that mass moment of inertia can be considered as a linear function of input current, provided the sensor rotates at constant rpm. As it is understood that there will be some initial mass moment of inertia $J$ (mass moment of inertia due to complete rotational system without ice) associated with the system hence motor would draw some fixed current $I$, and Equation 9 can be written as,

$$
J+\delta J_{i c e}=a\left(I_{i n}+\delta I_{\text {in }}\right)+b
$$


This $\delta J_{i c e}=m_{\text {ice }} R_{i c e}^{2}$ and $R_{i c e}$ is the radius of gyration of atmospheric ice, which is equal to $R_{\text {fins }} / \xi$ where $\xi$ is a forced rotation constant which lies in the interval $[0.5,1]$ and is assumed to be a function of Reynold number, rotational rate, supercooled water droplets freezing fraction [7] colliding with rotational part of the sensor and thickness of the rotating fins. An average value $\xi=0.7$ is considered for a standard material. Therefore a linear relationship between icing load and additional current can be written as,

$$
\delta m_{i c e}=A \delta I_{\text {in }}+B
$$

Equation 11

where $A=a / R_{\text {ice }}^{2}$ and $B=\left(a I_{\text {in }}-J+b\right) / R_{\text {ice }}^{2}$. Ideally $B=0$. Equation 11 is therefore named as Current - Mass or $\delta I-\delta m$ relation. Using the experimental results one can calibrate the constants $a$ and $b$ in Equation 11.

\section{Calibrating Current Sensor through Validating Motor Loading}

After the prototype manufacturing of new icing sensor [8], the sensor need to be tested for the uniform deposition of atmospheric ice around the complete rotational part for an adequate loading on the motor. The starting masses of different rotating parts of manufactured prototype of an icing sensor (see Figure $3 b$ ) are tabulated in Table 1.

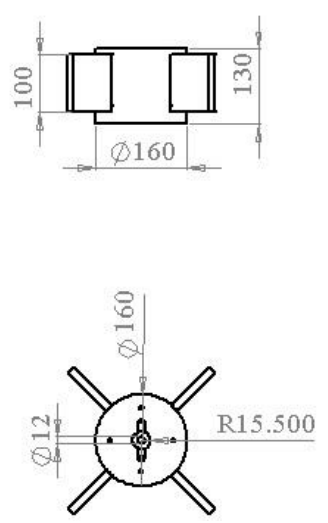

(a). Dimensions of Rotating cylinder with four fins,

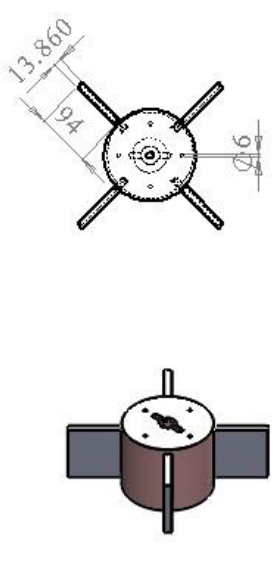

Figure 3. CAD Model of Prototype Icing Sensor

\begin{tabular}{|l|c|}
\hline Parts & Item Mass in grams \\
\hline Stationary Parts (Figure 3b) & 3350 \\
Mass of sensor base and motor housing (Sensor Base + Step Motor Unit) & 2650 \\
Mass of motor & 572 \\
\hline Rotational Parts (Figure 3) & 1308 \\
Mass of sensor shaft and bolt (Rotating Shaft + Top Bolt) & 190 \\
Mass of rotating cylinder & \\
Mass of fins & \\
\hline
\end{tabular}

Table 1. System parts and their masses

Before starting the actual experimentation of the prototype icing sensor, it was required to calibrate the sensing mechanism of the sensor. The current sensor used in the system was calibrated at a standard room temperature by measuring the digital output voltage due to varying rotating masses and rotational speed of the sensory system. The calibration was done under ideal conditions at room temperature to test the functionality of the motor under different rotational loadings. The calibration curves are shown in Figure 4. Using the calibration curve of current sensor as outlined in Figure 4, linear curve fitting equation were obtained for analog current in $m A$ vs digital voltage $m V$ (given by Equation 
12 and total mass moment of inertia $\mathrm{g} / \mathrm{mm}^{2}$ vs digital voltage $\mathrm{mV}$ (Equation 13) at fixed supply voltage of $30 \times 10^{3} \mathrm{mV}$,

$$
\begin{gathered}
I_{\text {calibration }}=11.583 V_{\text {measured }}-29513 \\
J_{\text {calibration }}=3.95 \times 10^{7} V_{\text {measured }}-1.0225 \times 10^{11}
\end{gathered}
$$

Equation 12

Equation 13

where $V_{\text {measured }}$ is measured voltage of the sensor which varies $0 \rightarrow 5000 \mathrm{mV}$ for the current variation $I_{\text {calibration }}$ which varies between $-30 \times 10^{3} \leftrightarrow 30 \times 10^{3} \mathrm{~mA}$ and $J_{\text {calibration }}$ is the total mass moment of inertia of prototype icing sensor. Here Equation 13 is found at 6rpm, therefore for different rpms' different relations can be found. Now using Equation 12 in Equation 13, the Current Inertia or I - J Calibration Relationship can be found and is given by Equation 14,

$$
J_{\text {calibration }}=3.41 \times 10^{6} I_{\text {calibration }}-1.606 \times 10^{9}
$$

Equation 14

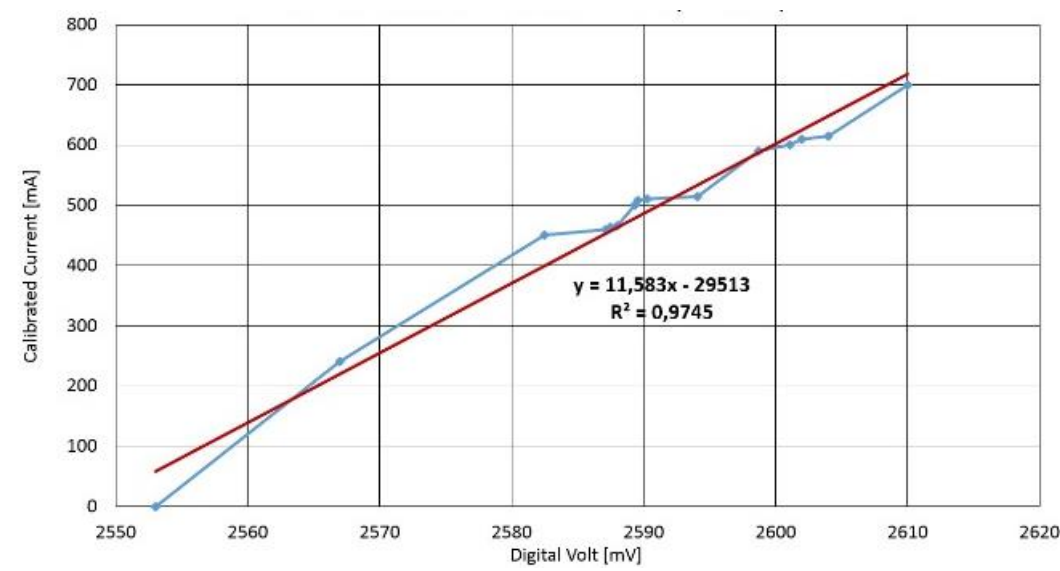

(a). Calibration Curve for Current Sensor (I - V Curve),

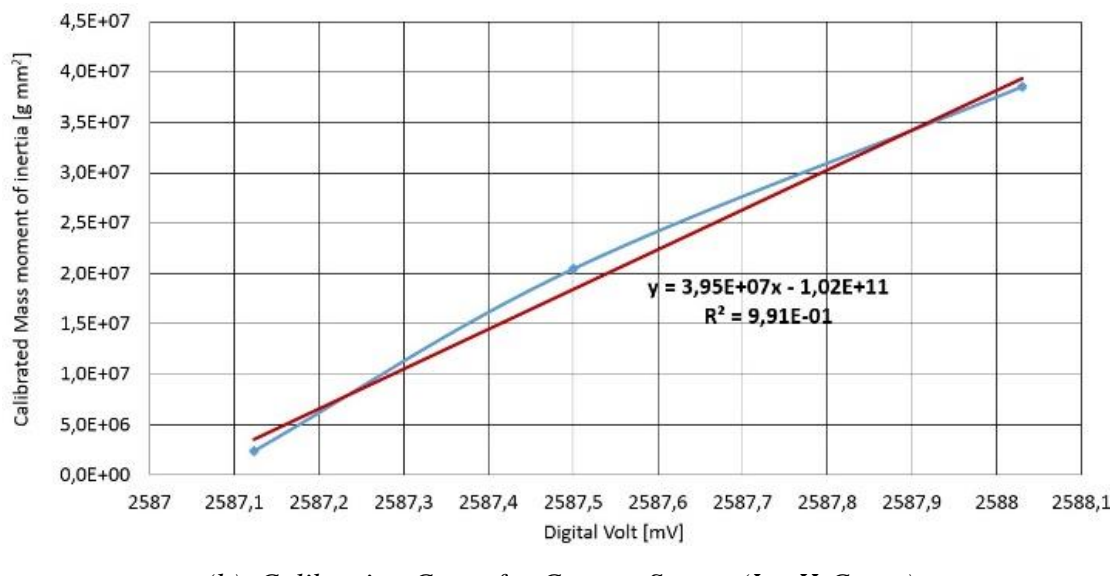

(b). Calibration Curve for Current Sensor (J - V Curve)

Figure 4. Current Sensor Calibration Graphs without ice at room temperature

As it is understood that the electrical output will be in the form of current, therefore based upon our assumption in 3.2, we assumed a forced rotation constant $\xi$. Therefore using $\xi=0.7$ in Equation 14, Calibrated $I-J$ Relationship, Equation 15 can be formed,

$$
J_{\text {calibration }}=2.387 \times 10^{6} I_{\text {calibration }}-1.606 \times 10^{9}
$$




\section{Cryospheric Environment Simulator CES, Shinjo Japan}

Cryospheric Environmental Simulator [9] is one of the four facilities of NIED [10] for performing basic and applied studies related with snow and ice disasters using a snow fall machine and icing wind tunnel. To validate the rotational physics for atmospheric icing sensor of Narvik University College, Cryospheric Environmental Simulator 'CES' was the most suitable choice. The test section dimension were $1 m \times 1 m$ as can be seen in Figure 5 .

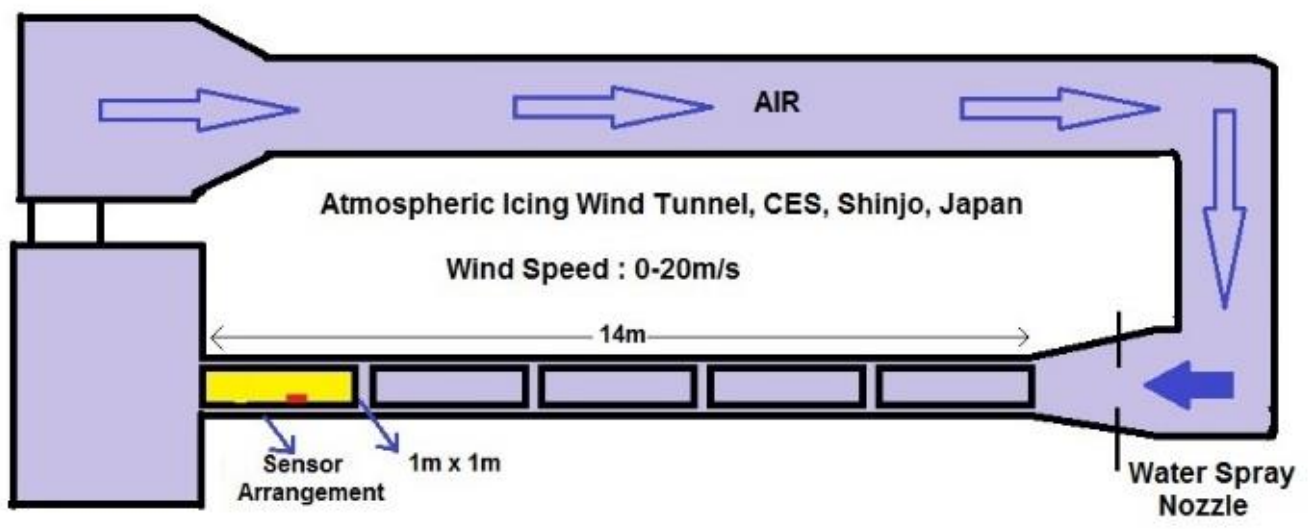

(a). CES Icing Wind Tunnel

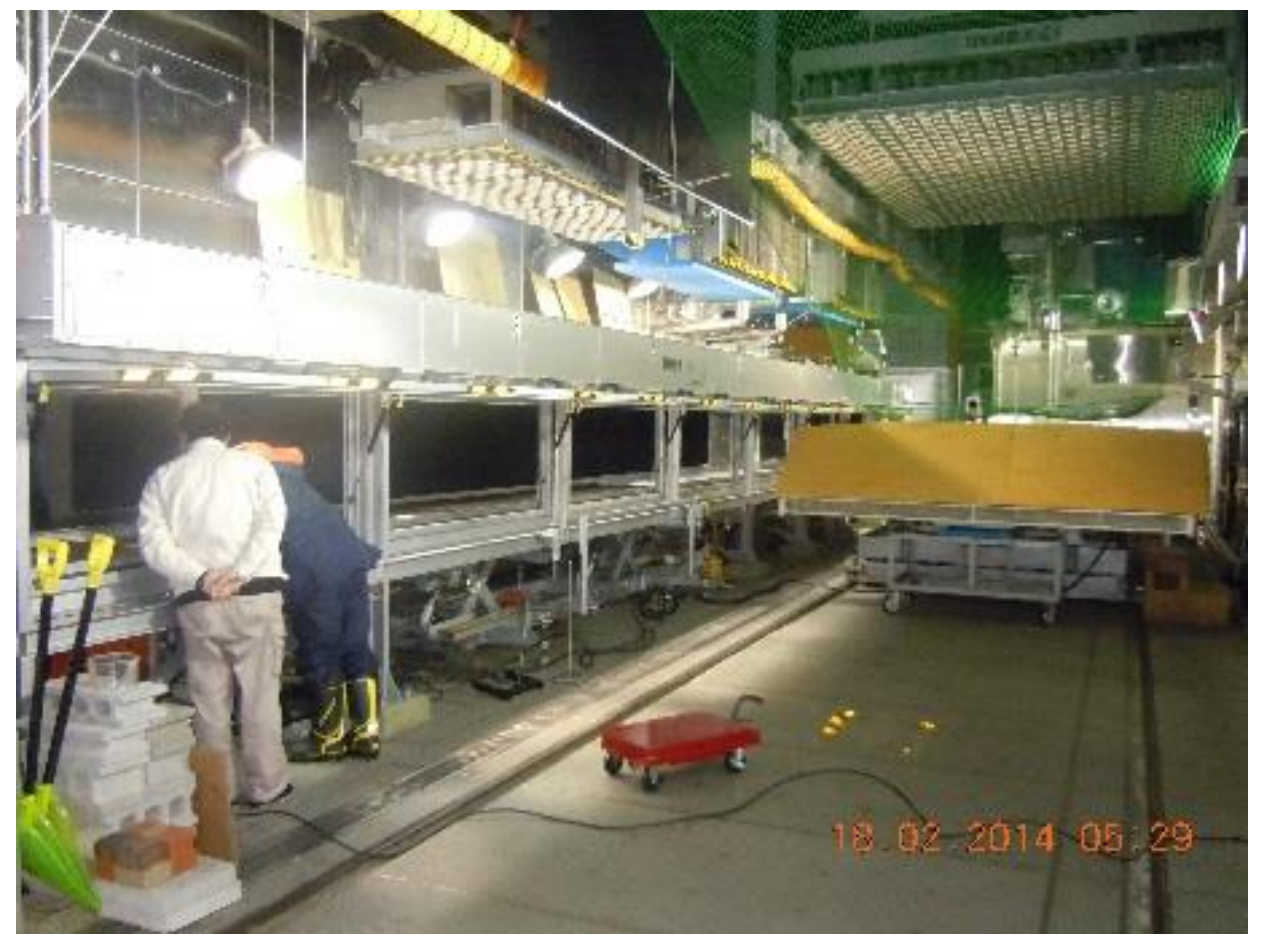

(b). CES Icing Wind Tunnel Test Section

Figure 5. CES Icing Wind Tunnel

During this phase of experimentation icing wind tunnel at CES was utilized. The ice was allowed to deposit on a cylinder with four fins (shown in Figure 3a) rotating at a constant rpm $\Omega_{m}=6$. During experimentation the base of the icing tunnel test section was used as a separation between rotating and stationary component as to simulate the rate and shape of ice accretion on the rotating part of the sensor only. The other prevailing environmental conditions around the sensor are provided in Table 2 . The actual liquid water content information was not available at the NIED experimental facility, however Figure 7 simply display the domain of probable values of LWC to be encountered during in-flight atmospheric icing. Also the complete experimental setup can be seen in Figure 6. IceMonitor ${ }^{\mathrm{TM}}$ [2] (a 
freely rotating sensor) was also used in order to understand difference in the dynamics of ice deposition on a system with forced rotation and freely rotation.

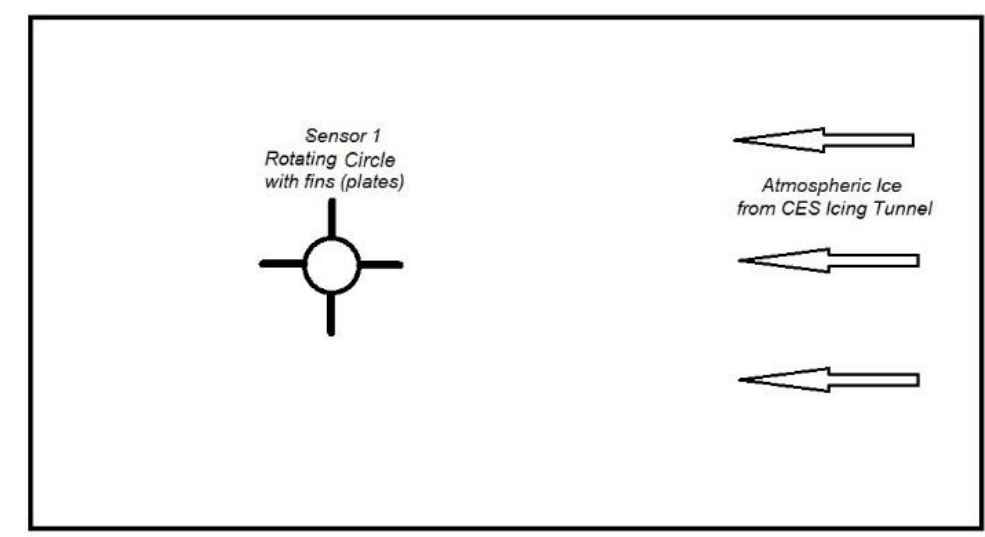

(a). Experimental Table - Top View

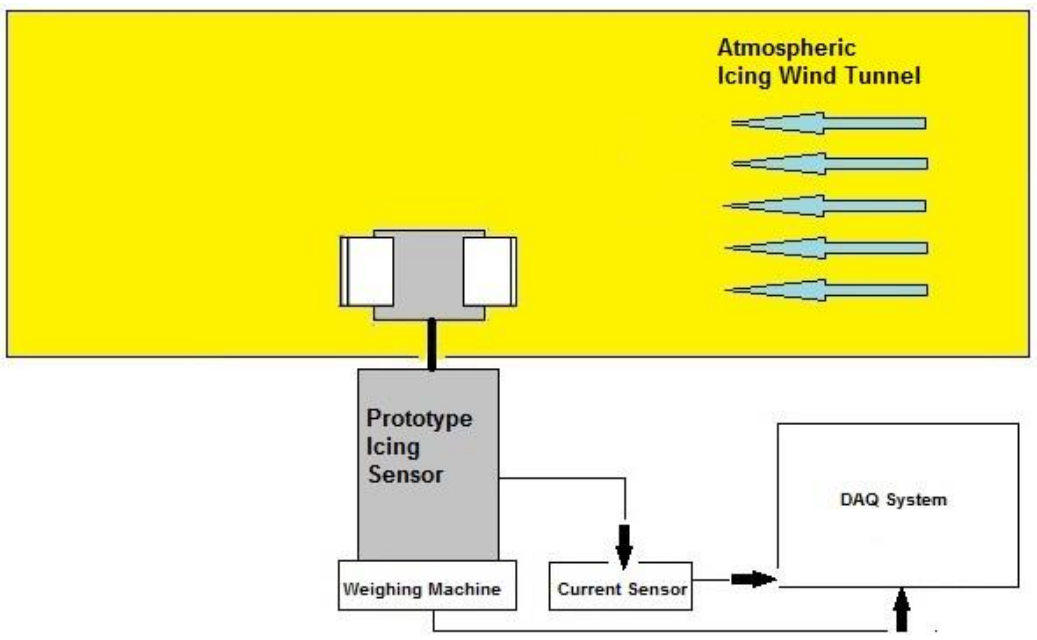

(b). Experimental Table - Side View

Figure 6. Experimental Setup, CES Japan

\begin{tabular}{|l|l|}
\hline \multicolumn{2}{|c|}{ Experimental Setup } \\
\hline Condition/Variables & Specifications \\
\hline Experimental Facility & CES Icing Wind Tunnel \\
\hline Sensor & Rotating cyliner with four fins \\
\hline Ice Type & Rime \\
\hline Droplet Spectrum & Fine mist $10 \rightarrow 100 \mu \mathrm{m}$ \\
\hline Liquid Water Content ${ }^{1}$ & $0.5 \rightarrow 0.1 \mathrm{~g} / \mathrm{m}^{3}$ (see Figure 7) \\
\hline Tunnel Temperature & $-15^{0} \mathrm{C}$ \\
\hline Time of Experiment & $110 \mathrm{~min}$ \\
\hline Wind Speed & $10 \mathrm{~m} / \mathrm{s}$ \\
\hline
\end{tabular}

Table 2. Experimental conditions for experiment

\footnotetext{
${ }^{1}$ Maximum probable values of LWC to be encountered during in-flight atmospheric icing but does not suggest the actual values of LWC during experiment
} 


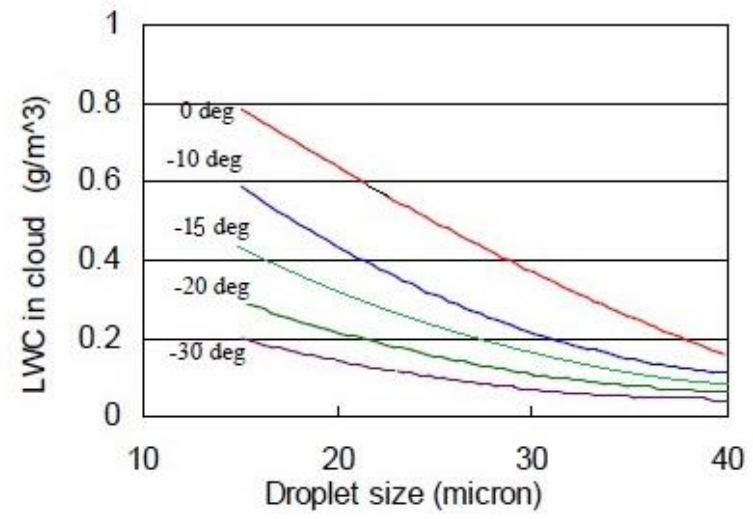

Figure 7. Relation of Liquid Water Content (LWC) and Droplet Size [11]

\subsection{Calculating Mass Moment of Inertia of Ice}

As mentioned before that the cylinder with plates was rotating around the shaft therefore its mass moment of inertia was calculated and the mathematical relations were developed (Figure $2 b$ and Equation 3) and the results are shown in Table 3. Here it is assumed that the mass of the atmospheric ice grow symmetrically around the fins which add into the actual mass of the plates. This extra mass of the accreted atmospheric ice $m_{i c e}$ is measured by a digital weighing machine placed under the experimental equipment. The mass of the atmospheric ice was then further used to determine the mass moment of inertia of the whole rotating system using Equation 16. This extra mass moment of inertia $J_{i c e}$ of the atmospheric ice with mass of the atmospheric ice $m_{i c e}$ is the main variable in the calculation therefore it is essential to compare the data between the actual mass moment of inertia and mass moment of inertia value delivered through the current sensor $I_{\text {measured }}$ through the final calibration equation Equation 14,

$$
J_{c c}=J_{c c_{\text {plate }}+\text { rotor }+ \text { shaft }}+J_{c c_{\text {ice }}}
$$

Equation 16

\begin{tabular}{|c|c|c|c|c|c|}
\hline Parts & $\begin{array}{c}\text { Mass, } M_{p} \\
\text { in ' } g \text { ' }\end{array}$ & $\begin{array}{l}\text { Number } \\
\text { of Parts }\end{array}$ & $\begin{array}{c}\text { Mass moment of } \\
\text { inertia around its } \\
\text { own axis, } \\
J_{\mathrm{ZZ}} \text { in ' } \mathrm{gmm}^{2},\end{array}$ & $\begin{array}{l}\text { Distance from } \\
\text { system central } \\
\text { axis, } d \text { in } \mathrm{mm}\end{array}$ & $\begin{array}{c}\text { Mass moment of } \\
\text { inertia around system } \\
\text { centroidal axis, } \\
J_{c c} \text { in ' } \mathrm{gmm}^{2} \text {, }\end{array}$ \\
\hline Shaft and bolt & 572 & 1 & $6.44 \times 10^{4}$ & 0 & $6.44 \times 10^{4}$ \\
\hline Fins & 190 & 4 & $5.72 \times 10^{5}$ & 126.5 & $7.05 \times 10^{6}$ \\
\hline Rotor & 1308 & 1 & $4.13 \times 10^{6}$ & 0 & $4.13 \times 10^{6}$ \\
\hline Ice & $m_{\text {ice }}$ & 4 & - & 126.5 & $J_{c c}=m_{\text {ice }} \frac{J_{c c_{\text {fins }}}}{\zeta M_{p_{\text {plate }}}}$ \\
\hline
\end{tabular}

Table 3. Mass Moment of Inertia Calculation of Slowly Rotating Cylindrical Sensor with Fins

\subsection{Experiment at CES}

This experiment was performed in wind tunnel of CES. The rotating part of the sensor was located near the test section floor as this setup was considered to be similar with the actual sensor where the bottom part is stationary and acting as a stationary ground for the rotating part. Also after experiment it was observed that due to the forced rotation mechanism the distribution of ice was uniform and no obvious ground effects were observed due to rotation. The measurement setup can be seen in Figure 8c. The calibrated relation between mass moment of inertia and current loading is given by Equation 17 whereas the experimental mass moment of inertia and current loading equation is given as Equation 18 and graphical results are shown in Figure 9a. As the prototype icing sensor rotating shaft was passing through the test section floor into the motor residing in the stationary part of the sensor therefore the diameter of the hole in the test section floor was critical. It was initially observed that reducing the diameter of the floor to $32 \mathrm{~mm}$ (prototype icing sensor's rotating shaft diameter was $30 \mathrm{~mm}$ ) was not 
suitable because the base of the icing tunnel test section was slightly vibrating as a function of wind speed and causes some unavoidable frictional effects due to frequent touching with the rotating shaft of the motor. It was tried to reduce this problem by slightly increasing the diameter of the test section floor, however this problem was not completely eradicated due to the constrain to not provide additional path to blowing wind. These small frictional effects were possibly amplifying the current requirement of the motor to maintain the rpm. However in actual condition there will be no such separation layer between the rotational unit and stationary unit of the sensor. Also due to the geometric constrain of the icing tunnel section size, it was not possible to mount the complete sensory unit (rotating and stationary). However inspite of such discrenpency the results are linear and reflecting a useful relationship.

As reflected in Figure 3a, the overall diameter of the rotating cylinder with fins was $L=348 \mathrm{~mm}$ and according to Duraisamy et. al. [12] if the wall distance (1000 $\mathrm{mm}$ in this case) is less than three times the chord (1044 $\mathrm{mm}$ in this case) then there can be a significant lift vector augmentation (compared to freestream test) both in steady and unsteady flows. On a typical lifting surface as like an airfoil [12], the direction of lift vector is orthogonal to the lifting surface therefore the vertical height of the tunnel is considered as a reference dimension. Similarly on rotating non stream-line geometries as like the rotating cylinder with fins the direction of lift vector is again orthogonal to the rotating surface, in the radial direction which in our case is sideways therefore the width of the tunnel is considered as the reference dimension. Therefore it is assumed that the results of [12] may still be applied. Although the direct effect of this lift vector will not be much significant as the rpm is quite low but nevertheless the three dimensional/end effects (tip vortices) may be responsible for the increase in the value of lift coefficient compared with that achieved in a purely two dimensional flow. It may also be one of the possible reason of deviation between calibrated and experimental $I-J$ relation. Also as calculated the Reynold Number of this experiment is approximately $R e=265802(R e=\rho v L / \mu)$ and the rotational rate is calculated as $\alpha=0.019(\alpha=L \Omega / \mathrm{v})$ which reflect the flow is turbulent and vortex shedding can be observed as $\alpha<1.91$, for details see Mittal and Kumar [13]. Therefore the wall and boundary effects may be significant during this experiment. The mass current relation of Prototype Icing Sensor was also determined experimentally and is given by Equation 19 and the graphical representation can be seen in Figure 9b.

$$
\begin{gathered}
I_{\text {calibrated }}=4.16 \times 10^{-7} J_{\text {experimental }}+469 \\
I_{\text {experimental }}=4.13 \times 10^{-6} J_{\text {experimental }}+429 \\
\delta I=0.153 \delta m+6.141
\end{gathered}
$$

Equation 17

Equation 18

Equation 19

To compare the values of $A, B, a$ and $b$, Equation 17, Equation 18 and Equation 19 can be rewritten as Equation 20, Equation 21 and Equation 22 respectively.

$$
\begin{gathered}
J_{\text {MuVi }_{\text {experimental }}=}=2.40 \times 10^{6} I_{\text {calibrated }}-1.12 \times 10^{9} \\
J_{\text {MuVi }_{\text {experimental }}=}=2.42 \times 10^{5} I_{\text {experimental }}-1.03 \times 10^{8} \\
\delta m=6.5 \delta I-40
\end{gathered}
$$$$
\text { Equation } 20
$$$$
\text { Equation } 21
$$ 


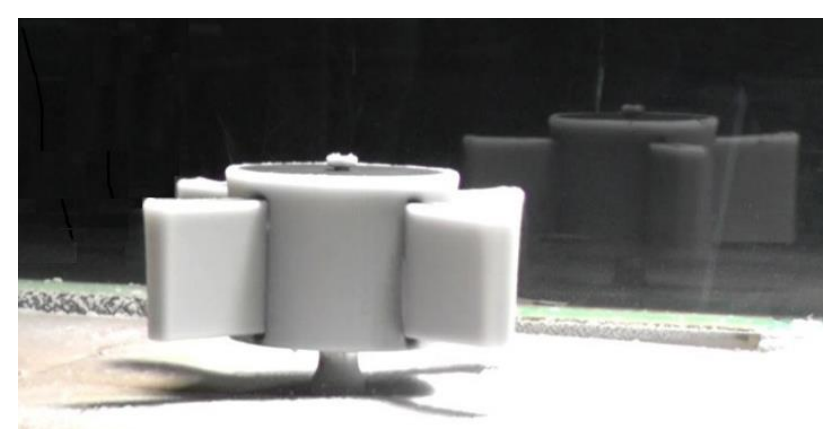

(a). Sensor Arrangement - Side View

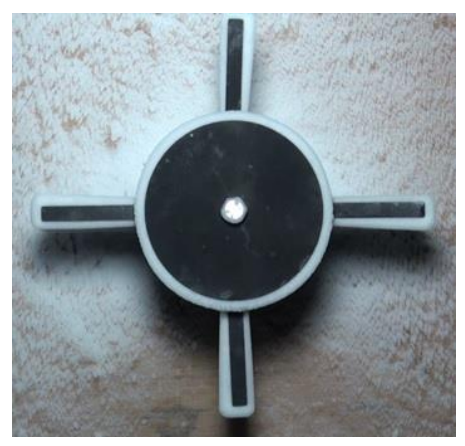

(b). Sensor Arrangement - Top View

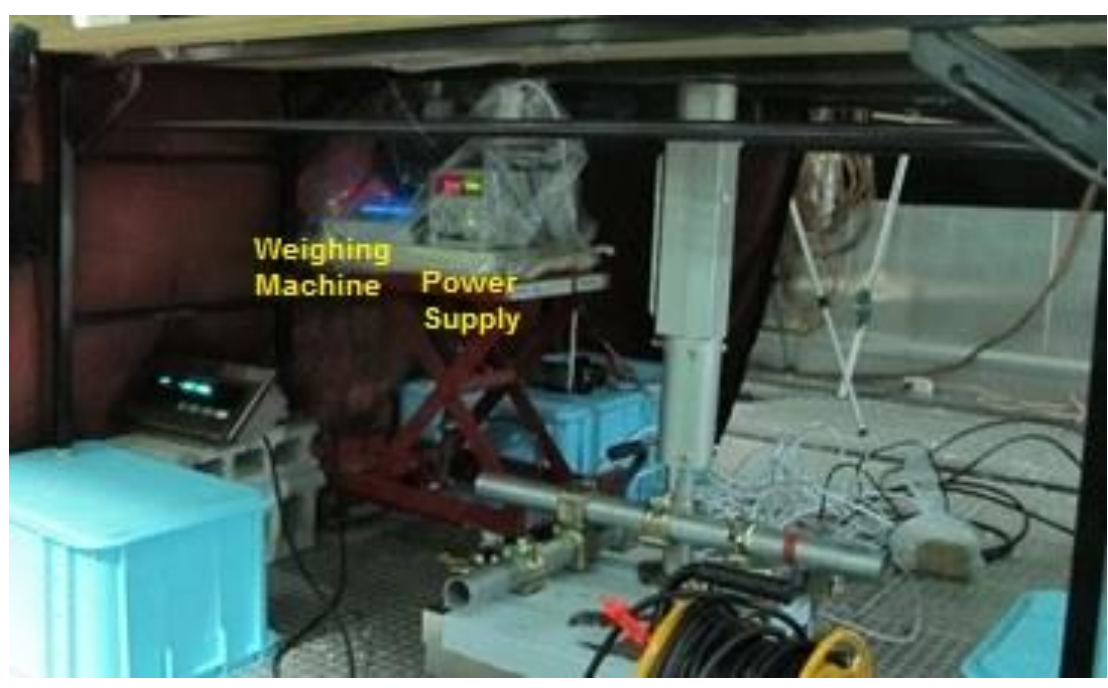

(c). Measurement Setup

Figure 8. Experimental Setup in Icing Tunnel

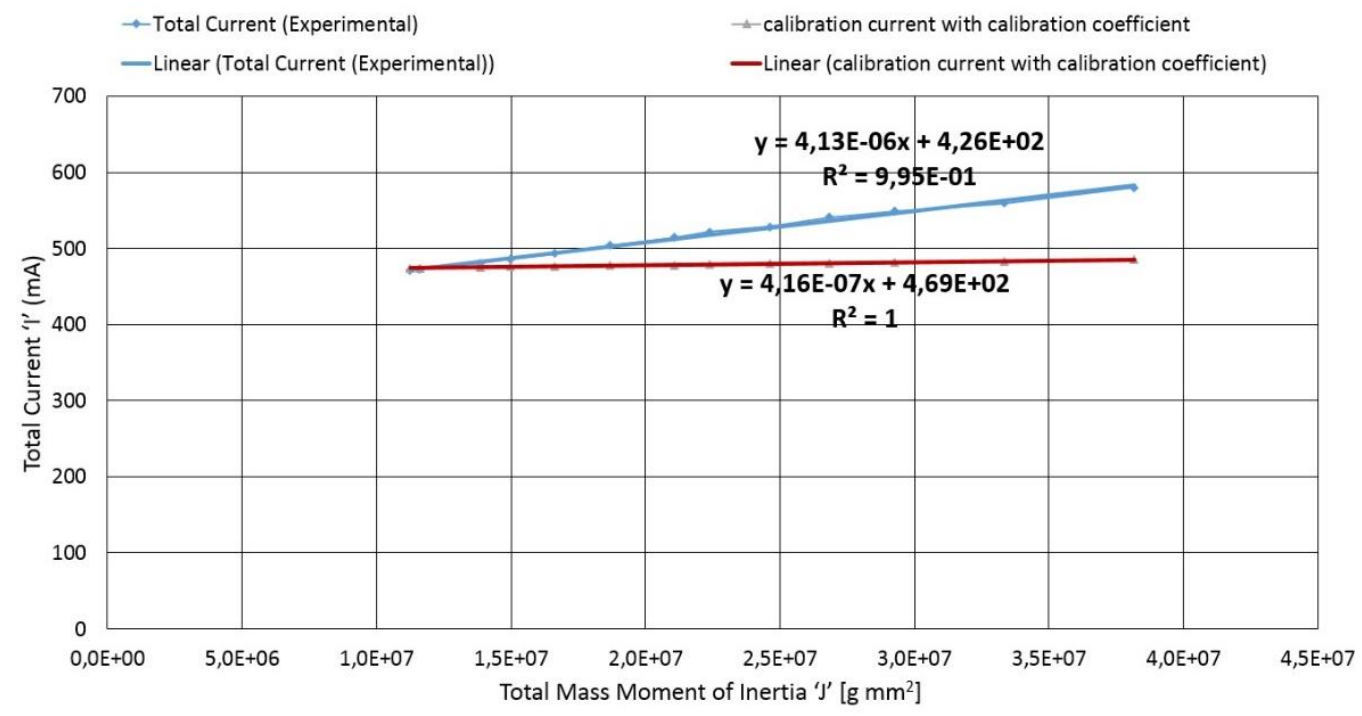

(a). Current - Inertia or I - J Curve 


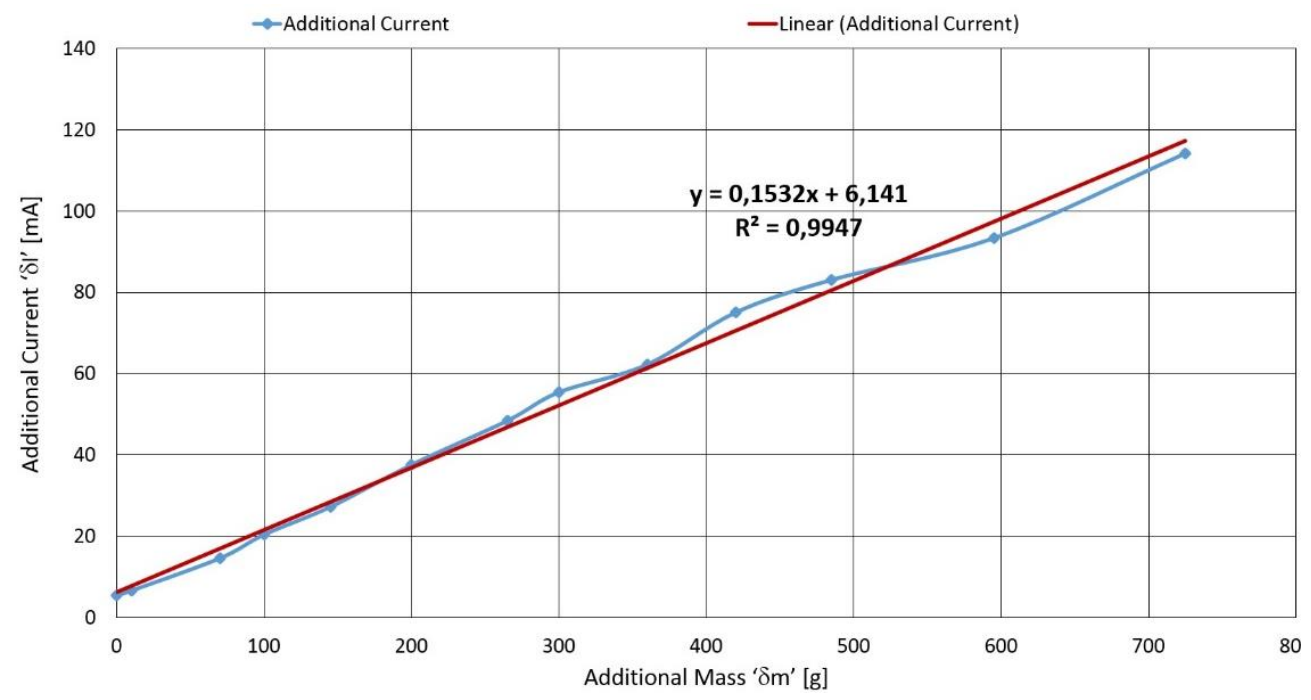

(b). Current - Mass or $\delta I-\delta m$ Curve

Figure 9.Graphical Results of Experiment in Icing Wind Tunnel

\section{Co-efficients Comparision}

Using the analytical relations Equation 9 and the experimental prevailing conditions values of $a$ and $b$ were calculated which are given in Table 4. Also a comparison of the values of $a$ and $b$ (analytical, experimental Equation 21 and calibrated Equation 14 are shown in Table 4.

\begin{tabular}{|c|c|c|c|c|c|c|c|c|c|c|}
\hline & \multirow[b]{2}{*}{ Formula } & \multicolumn{6}{|c|}{ Other Constants } & \multicolumn{3}{|c|}{ Measured and Calculated Coefficient Values } \\
\hline & & $\begin{array}{l}V_{i n} \\
m V\end{array}$ & $\begin{array}{c}\Omega_{m} \\
\mathrm{rad} / \mathrm{s}\end{array}$ & $\alpha$ & $\beta$ & $\gamma$ & $\begin{array}{c}\eta \\
\text { Watts }\end{array}$ & Analytical & Calibrated & Experimental \\
\hline$a$ & $\frac{\alpha V_{\text {in }}}{\beta \gamma \Omega_{m}^{3}}$ & \multirow{2}{*}{30000} & \multirow{2}{*}{0.628} & \multirow{2}{*}{0.7} & \multirow{2}{*}{0.7} & \multirow{2}{*}{0.7} & \multirow{2}{*}{$10 \% P_{\text {in }}$} & $\begin{array}{l}1.73 \times 10^{5} \\
g m m^{2} / A\end{array}$ & $\begin{array}{c}2.40 \times 10^{6} \\
g \mathrm{gm}^{2} / A\end{array}$ & $\begin{array}{c}2.42 \times 10^{5} \\
g^{2} m^{2} / A\end{array}$ \\
\hline$b$ & $\frac{-\eta}{\beta \gamma \Omega_{m}^{3}}$ & & & & & & & $\begin{array}{c}-1.23 \times 10^{7} \\
g m m^{2}\end{array}$ & $\begin{array}{c}-1.12 \times 10^{9} \\
\mathrm{gmm}^{2}\end{array}$ & $\begin{array}{c}-1.03 \times 10^{8} \\
g m m^{2}\end{array}$ \\
\hline
\end{tabular}

Table 4. Values of Co-efficients $\mathrm{a}$ and $\mathrm{b}$

Similarly using the analytical relations Equation 11 and the experimental prevailing conditions value of $A$ was calculated which is given in Table 5. Also a comparison of the values of $A$ (analytical and experimental Equation 22) is shown in Table 5.

\begin{tabular}{|c|c|c|c|c|c|c|c|c|}
\hline \multirow{2}{*}{} & \multirow{3}{*}{ Formula } & \multicolumn{9}{|c|}{ Other Constants } & \multicolumn{2}{c|}{$\begin{array}{c}\text { Measured and Calculated } \\
\text { Coefficient Values }\end{array}$} \\
\cline { 3 - 8 } & & $\begin{array}{c}a \\
g m m^{2} / A\end{array}$ & $g m m^{2}$ & $\begin{array}{c}R_{\text {plates }}^{2} \\
m^{2}\end{array}$ & $\begin{array}{c}I_{\text {in }} \\
m A\end{array}$ & $g m^{2}$ & Analytical & Experimental \\
\hline \multirow{2}{*}{$A$} & $\frac{a}{\zeta R_{\text {plates }}^{2}}$ & $1.73 \times 10^{5}$ & $-1.23 \times 10^{7}$ & $3.7 \times 10^{4}$ & 500 & $4.76 \times 10^{6}$ & 6.68 & 6.5 \\
\hline
\end{tabular}

Table 5. Values of Coefficient A 


\section{Conclusion}

Experimental testing of prototype icing sensor for rotational loading proves the associated physics for an adequate measurement of icing load and icing rate. In this paper, it was aimed to mathematically model the ice growth rate around a rotational prototype sensor in order to calculate the icing load and icing rate by measuring the variation in the current demand. The focus of this experiment was to compare the analytical, calibrated and experimental values of the parameters $a, b$ and $A$. After looking at Table 4 and Table 5, it can be conveniently deduced that although there is a deviation between the experimental, calibrated and analytical values due to natural constraints of lab based experimentation in the icing tunnel (size, scaling etc) but nevertheless the results were linear and hence the results can be more improved by introducing some other constants in the calibration equation depending upon the experimental boundary conditions. Based upon this understanding forced rotation constant $\xi=0.7$ (which is dependent upon the freezing fraction, reynold number, rotational rate and thickness of the rotating fins) is introduced into the analytical and calibration relationships. After experiment it was observed that due to the rotation mechanism the distribution of ice was uniform and no obvious ground effects were visible due to rotation. There were no clear indications of ice deposition between the sensor and the test section base and even on the sensor top surface, which may be due to the vorticity of the rotating cylinder. In another experiment these ground effects were prominent on ice load monitor and non rotating polygon. Here it is also found that if the rotating fins are assumed to be some electrode plate with some necessary circuitry inside the rotating cylinder then adequate deposition of atmospheric ice on the plates may support the electronic measurements to some extent. It is mentioned in Cost 727 that a slowly rotating sensor may provide a better ice deposition and icing load characteristics, hence this testing may support this to a reasonable level based upon constantly slowly rotating cylinder with four fins.

\section{Acknowledgment}

This research work is funded by Research Council of Norway, project no. $\$ 195153 \$$ and partially by the consortium of the ColdTech RT3 project - Sustainable Cold Climate Technology. Also we acknowledge Cryospheric Environmental Simulator, Shinjo, Japan staff for their support and facility during the experimentation.

\section{References}

1. Ryerson, C.C., Assessment of Superstructure Ice Protection as Applied to Offshore Oil Operations Safety. Cold Regions Research and Engineering Laboratory, 2009.

2. Ice Load Monitor Webpage. 2014 [cited 2014 September 10]; Available from: http://www.combitech.com/Documents/Bilder\%20och\%20filer\%20sidor/Tj\%C3\%A4nster/En vironmental\%20Solutions/IceMonitor_Produktblad_Combitech.pdf.

3. Ice Meter. 2014 [cited 2014 September 10]; Available from: http://www.ufa.cas.cz/html/upperatm/chum/namraza/Icingmeasczech2.pdf.

4. Holo Optic Icing Rate Sensor. [cited 2016 20th January]; Available from: http://holooptics.utrymmet.com/Dokument/651.Userguide\%20T40.004.En.pdf.

5. $\quad$ Fikke, S., COST 727: Atmospheric icing on structures, measurement and data collection on icing, state of the art. 2006, MeteoSwiss. p. 110.

6. Fishbane, P.M., S. Gasiorowics, and S. Thornton, Physics - for Scientists and Engineers, ed. P. Hall. 1996.

7. Drage, M., Atmospheric icing and meteorological variables - Full Scale Experiments and Testing of Models, in Department of Geophysics. 2005, Bergen University, Norway.

8. Mughal, U.N. and M.S. Virk. Cognitive Decision Making for measuring icing load for Cold Regions. in CogInfoComm. 2014. Vietri Sul Mari, Salerno, Italy. 

$C E S$, Shinjo,

http://www.bosai.go.jp/seppyo/jikkentou/jikkentou_syoukai_e.html.

10. NIED Japan. Available from: http://www.bosai.go.jp/e/.

11. Kimura, S., et al. Evaluation of ice detecting sensors by icing wind tunnel test. in IWAIS XIII Proceedings. 2009. Andermatt.

12. Duraisamy, K., W.J. McCroskey, and J.D. Baeder, Analysis of Wind Tunnel Wall Interference Effects on Subsonic Unsteady Airfoil Flows. Journal of Aircraft, 2007. 44(5).

13. Mittal, S. and B. Kumar, Flow past a rotating cylinder. Journal of Fluid Mechanics, 2003. 476: p. 32. 